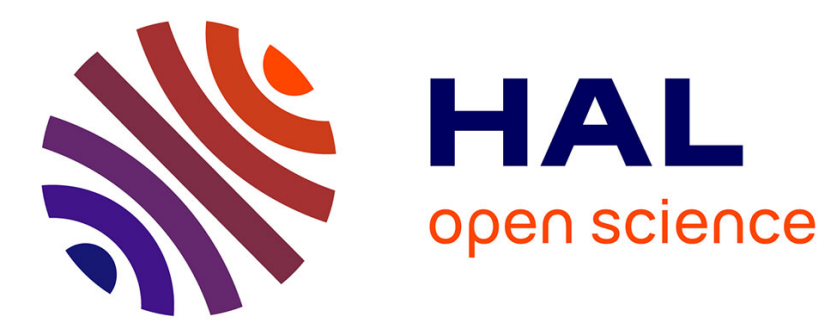

\title{
The relationship between meaning and intonation in non-exhaustive answers: evidence from Basque
}

\author{
Gorka Elordieta, Aritz Irurtzun
}

\section{To cite this version:}

Gorka Elordieta, Aritz Irurtzun. The relationship between meaning and intonation in non-exhaustive answers: evidence from Basque. 2011. artxibo-00645207

\section{HAL Id: artxibo-00645207 https://artxiker.ccsd.cnrs.fr/artxibo-00645207}

Preprint submitted on 27 Nov 2011

HAL is a multi-disciplinary open access archive for the deposit and dissemination of scientific research documents, whether they are published or not. The documents may come from teaching and research institutions in France or abroad, or from public or private research centers.
L'archive ouverte pluridisciplinaire HAL, est destinée au dépôt et à la diffusion de documents scientifiques de niveau recherche, publiés ou non, émanant des établissements d'enseignement et de recherche français ou étrangers, des laboratoires publics ou privés. 


\title{
The relationship between meaning and intonation in non-exhaustive answers: evidence from Basque
}

\author{
Gorka Elordieta ${ }^{a}$ and Aritz Irurtzun ${ }^{b}$ \\ University of the Basque Country and University of the Balearic Islands \\ ${ }^{\mathrm{b}}$ University of the Basque Country
}

\begin{abstract}
In this paper we analyze the intonational properties of a type of focus construction that has been understudied, represented by answers to $w h$-questions in which the constituent that fills the variable does not do so exhaustively, that is, it does not provide an exhaustive answer because the speaker cannot commit to asserting that the other potential alternative candidates to fill the variable are cancelled. This type of narrow focus, Non-Exhaustive Narrow Focus (NENF), is different from Exhaustive Narrow Focus (ENF), in which a constituent fills the variable of the question exhaustively, with a concomitant cancellation of the rest of the focal alternatives. Our claim is that natural languages have the means to distinguish ENF and NENF unambiguously through prosodic means. In the present study, we show that speakers of (Northern Bizkaian) Basque assign particular intonational features to answers to $w h$-questions that should be interpreted non-exhaustively. In our experiment, we measured peak scaling of accents in the subject and the verb in ENF and NENF utterances. The results show that NENF is distinguished from ENF in having a pitch accent on the verb with a higher F0 value, almost as if the verb were focalized. In fact, we compared the intonational patterns of NENF with Verum Focus constructions, in which the polarity of the event expressed by the verb is focalized, and there were no significant differences in the verbal peaks in NENF and VF. There were no significant differences in peak scaling in the subject's stressed syllable between ENF and NENF, and neither were there any differences between NENF and VF. The paper offers a semantic analysis of the differences between ENF and NENF, by claiming that NENF is a split focus construction, in which both the subject and the polarity (or rather, the pairing between the subject and the polarity) constitute the focus of the utterance.
\end{abstract}

\section{Introduction*}

Usual analyses of the semantics of questions à la Hamblin (1973) and Karttunen (1977) propose that an answer to a $w h$-question like (1b) picks up one proposition of the denotation of the question (1a) (which is the set of propositions obtained by the substitution of the wh-phrase by contextually available alternatives that match it in semantic type). This provides an answer to the question.

(1) a. Who loves Paula?

$\{\operatorname{love}(\mathrm{x}, \mathrm{p}) \mid \mathrm{x} \in E\}=\{[[$ Mary loves Paula] $]$, [[John loves Paula] $]$, [[Peter loves Paula $]$, [[Sarah loves Paula $]$, [[George loves Paula $]$ ]...

b. Mary loves Paula.

$\{$ love $(\mathrm{m}, \mathrm{p})\}=[[$ Mary loves Paula $]]$

However, there are other cases where an answer to a wh-question may provide such a

\footnotetext{
We are deeply grateful to the speakers of the experiment presented in this paper, as well as to two anonymous reviewers for their helpful comments. This article is based on parts of the material presented at the workshop Experimental Studies on Intonation: Phonetic, Phonological and Psycholinguistic Aspects of Sentence Prosody (University of Potsdam, January 5-7, 2009), the workshop Mapping Asymmetries: Phonology, Syntax and Information Structure (Thessaloniki, April 3-5, 2009), the conference Phonetics and Phonology in Iberia 2009 (Universidad de Las Palmas de Gran Canaria, June 17-18, 2009), and the Workshop on Prosody and Meaning (Barcelona, September 17-18, 2009). We want to thank the audiences at those events for constructive feedback. This work was made possible by funding from the Spanish Ministry of Science and Innovation/FEDER (research projects HUM2006-12695, FFI2008-04789/FILO and Consolider-Ingenio 2010 research project CSD2007-00012) and from the Basque Government (Research Group in Theoretical Linguistics/HiTT, ref. GIC07/144-IT-210-07).
} 
proposition but without answering the question fully. E.g., (1a) could be answered as the one in (1b) but implying that there might be other potential lovers of Paula, for which the speaker has no evidence; i.e., the open set denoted by the question is not cancelled by the answer. This type of answers could be paraphrased as I know that Mary loves Paula, but I'm not saying Mary is the only one loving Paula; there could be more people besides Mary that love Paula. We refer to this type of answers as Non-Exhaustive Narrow Focus (NENF), opposed to Exhaustive Narrow Focus (ENF). This dichotomy between ENF and NENF is not new in the literature on focus in generative grammar (cf. É. Kiss 1998, Kenesei 2006, Molnár 2006, Horvath 2010, among others). The answer in (2b) to an open question like (2a), without a closed candidate set mentioned in the discourse or present in the speaker and hearer's minds, could, in principle, be interpreted exhaustively or nonexhaustively. That is, it could be that John only bought potatoes and nothing else, or it could be that John bought potatoes among other things.

(2) a. What did John buy?

b. John bought potatoes.

With a closed candidate set, an answer to a wh-question tends to be understood exhaustively, as the members of the candidate set are understood as exclusive disjunctions:

(3) a. What did John buy? Potatoes, carrots, onions, or peppers?

b. John bought potatoes.

An interesting aspect of the alleged ambiguity in (2b) is that both types of answers with narrow focus on potatoes are assumed to be pronounced with the same intonation contour. While we do not dispute this possibility, in this paper we want to argue that languages can cue the distinction between ENF and NENF prosodically. We will present evidence from Northern Bizkaian Basque showing that NENF is encoded intonationally. In answers to subject wh-questions, the subject does not receive main prominence in NENF, unlike in ENF. In this language, ENF on the subject is signaled through strict peak alignment on the stressed syllable followed by pitch compression, without an accent on the verb. With NENF on the subject, however, the verb does show a pitch accent, although downstepped with respect to the one in the subject. The presence of a pitch accent on lexically unaccented participial verbs such as the ones in our corpus is only expected when the verb is the narrow focus of the utterance, not when the subject is. The most common type of answer to a subject wh-question is one with ENF on the subject, in which the subject gets nuclear stress. However, in NENF answers there is an additional tonal gesture on the verb. But then, the interest of NENF constructions lies not only on the differences with ENF, but also on the similarities with another type of construction in which it is not the subject that constitutes narrow focus but the polarity of the even expressed by the verb. These are verum focus constructions (VF). In VF, it is the polarity, which is expressed in the inflection, which is the focus of the sentence (cf. the dialogue in (4)).

$$
\begin{array}{ll}
\text { A: } & \text { - I'm not sure whether Mary loves Paula. } \\
\text { B: } & \text { - Mary does love Paula. }
\end{array}
$$

As said, here we will concentrate on the differences and similarities between ENF and NENF on the one hand and NENF and VF on the other through an experimental study of the intonational contours of these constructions in Northern Bizkaian Basque. This investigation is part of a broader project that aims at comparing NENF with other constructions with which in principle it has partial similarities. These would be constructions with an information structure in which the subject bears a pitch accent but is not the narrow focus of the utterance, such as broad focus sentences and sentences with the subject as a topic or as given information. Additionally, we aim to study whether the differences between ENF and NENF in answers to subject $w h$-questions also hold 
in multiple wh-questions, of the type Who saw whom?, so this type of sentences were also included in the experimental database. But for the purposes of this paper, we will only deal with ENF, NENF and VF Finally, since our hypothesis is that NENF is a subtype of narrow focus construction existing in all languages (thus part of grammar and human language), our ongoing project also includes Spanish and French as test languages (see Elordieta and Irurtzun in prep). The relevance of our study lies in the fact that the intonational properties of NENF have not been analyzed so far in the literature on the prosodic correlates of focus.

In section 2 we present the semantic frame where we set our discussion. We give an overview of the semantics of interrogatives and present the notions of complete and partial answers (which correspond to ENF and NENF, respectively). In section 3 we present the methodology of our experimental study based on Northern Bizkaian Basque. Section 4 presents the results of the experiment and section 5 is devoted to their discussion and analysis. Finally, in section 6 we discuss some issues for further research.

\section{The semantics of questions}

In order to clarify the type of cases that we will be focusing on in this paper, we will start by introducing the 'Partition Semantics' approach to the interpretation of interrogatives, as proposed in works like Higginbotham and May (1981) or Groenendijk and Stokhof (1982). These authors have argued that a question like (5) demands two pieces of information in order to be completely answered, (5i) and (5ii):

(5) Who read Gramatika bideetan?

(i) Who read Gramatika bideetan?

(ii) Who did not read Gramatika bideetan?

That is, in order to know the answer to question (5) it will not be enough to know what satisfies the variable in the question; rather, the answer also has to provide in some way the negative information of (5ii) in order to be a satisfactory answer.

This intuition is clearer if we look at questions in embedded contexts like the one in (6):

(6) Patxi knows who read Gramatika bideetan .

In order for the sentence in (6) to be truthfully uttered, Patxi has to know (within a restricted domain of discourse) who read Gramatika bideetan and who did not, that is, he has to know how to split the group of the potential readers into the group of people that did read Gramatika bideetan and the group of people that did not read it. As an illustration, imagine the following situation: there is a group $\mathrm{G}$ of potential readers of Gramatika bideetan, where $\mathrm{G}=\{\mathrm{Jon}$, Xabier, Myriam, Pablo, Gorka, Aritz $\}$, and the actual readers of Gramatika bideetan form a subset R of G, where R $=\{$ Jon, Xabier, Myriam, Pablo\}. Even if Patxi knows that Jon, Xabier, Myriam and Pablo did read Gramatika bideetan, if he does not know whether the rest of the members of G (Gorka, Aritz) read Gramatika bideetan or not, he will not actually know who read Gramatika bideetan, i.e., he will not really know who constitutes the set R. In other words, in order for (6) to be true, Patxi has to know that the people he knows that read Gramatika bideetan is all the people that read it, but that is tantamount to knowing who read it and who did not read it.

Thus, a way of formulating this double requirement of a question in set-theoretic terms is to assume that a question creates a partition of the world into mutually exclusive states of nature, where a "partition" is defined as in (7), taken from Lahiri (2002):

\section{Partition}

$\mathrm{X}$ is a partition on a set $\mathrm{S}$ iff $\mathrm{X}$ is a set of non-empty sets such that (i) $\cup \mathrm{X}=\mathrm{S}$, and (ii) for any $Y, Z \in X$, if $Y \neq Z$, then $Y \cap Z=\varnothing$ 
Under this approach, then, a question like (8a) would create a partition like the one in (8b), a set of propositions where each of them is a complete specification of possible states of nature:

(8) a. Who read Gramatika bideetan?

b. If $\mathrm{p}_{1}, \ldots, \mathrm{p}_{\mathrm{n}}$ are the people in the world, then

[[who read Gramatika bideetan $]]=\{$

that $\mathrm{p}_{1}, \ldots, \mathrm{p}_{\mathrm{n}}$ read Gramatika bideetan

that $\mathrm{p}_{1}$ read Gramatika bideetan, $\mathrm{p}_{2}, \ldots, \mathrm{p}_{\mathrm{n}}$ did not read Gramatika bideetan

that $\mathrm{p}_{2}$ read Gramatika bideetan, $\mathrm{p}_{1}, \ldots, \mathrm{p}_{\mathrm{n}}$ did not read Gramatika bideetan

that $\mathrm{p}_{1}, \mathrm{p}_{2}$ read Gramatika bideetan, $\mathrm{p}_{3}, \ldots, \mathrm{p}_{\mathrm{n}}$ did not read Gramatika bideetan

...

that $\mathrm{p}_{1}, \ldots, \mathrm{p}_{\mathrm{n}}$ did not read Gramatika bideetan $\left.\quad\right\}$

It can be seen that each of the propositions in the set in $(8 b)$ is mutually exclusive with the others, because each of the propositions specifies for all the potential readers $\left(p_{1}, p_{n}\right)$ whether they read it or not.

Thus, assuming that this is the correct characterization of the import of a question, we can now formulate two different types of answers: 'complete answers' and 'partial answers'. Following Lahiri (2002), we can define them as follows:

Complete Answer

A proposition $\mathrm{p}$ is a complete answer to a question $\mathrm{Q}$ iff $\mathrm{p}$ is compatible with exactly one $\mathrm{q}$ $\in \mathrm{Q}$, i.e., iff there is exactly one $\mathrm{p} \in \mathrm{Q}$ such that $\mathrm{p} \cap \mathrm{q} \neq \varnothing$.

\section{(10) Partial Answer}

A proposition $\mathrm{p}$ is a partial answer to a question $\mathrm{Q}$ iff $\mathrm{p}$ is incompatible with at least one $\mathrm{q} \in$ $\mathrm{Q}$, i.e., iff there is at least one $\mathrm{p} \in \mathrm{Q}$ such that $\mathrm{p} \cap \mathrm{q}=\varnothing .^{1}$

So, having defined the notions of complete answer and partial answer, the next question is the following one: how do we obtain a complete answer from an answer such as (12), a response to a previous question (11)?

(11) Who drank wine?

(12) Nagore drank wine.

In principle, sentence (12) only seems to provide a partial answer to question (11), the positive information expressed by the proposition [[that Nagore drank wine]]. The negative side of the necessary information to complete the answer is missing, i.e., who did not drink wine. Following Irurtzun (2007), we will assume that, pragmatically, question-answer interpretations are two-sided processes of a Gricean reasoning ( $c$ f. i.a. Grice 1975, Horn 2004, as well as Spector 2006). As is well known, Grice (1975) proposed a set of 'maxims of conversation', which we list in (13):

(13) Gricean Maxims of Conversation

\section{Quantity:}

(i) Make your contribution as informative as is required (for the current purposes of the exchange).

(ii) Do not make your contribution more informative than is required.

\footnotetext{
${ }^{1}$ Other approaches like the 'Structured Meanings' approach of Krifka (1999) assume an exhaustifying operator to the same end, Assert(M, A, c) (“a sentence with meaning M and alternatives A in a context c is asserted"):

- the speaker claims $M$ (in c).

- for every alternative $M^{\prime} \in A, M^{\prime} \neq M$, the speaker explicitly does not claim $M^{\prime}$ (in c).
} 
Quality:

Supermaxim: Try to make your contribution one that is true.

(i) Do not say what you believe to be false.

(ii) Do not say that for which you lack adequate evidence.

Relation: Be relevant.

\section{Manner:}

Supermaxim: Be perspicuous.

(i) Avoid obscurity of expression.

(ii) Avoid ambiguity.

(iii) Be brief (avoid unnecessary prolixity).

(iv) Be orderly.

According to Irurtzun (2007), a typical answer to a wh-question like (11) implies as a first step a partial answer interpretation that provides the informativity of the content or, in Gricean terms, "what is said' by the proposition expressed by the sentence, i.e., that Nagore drank wine. This meaning is obtained via the standard compositional semantics. But this positive information is not sufficient to obtain a complete answer, that is, who did and did not drink wine. The first submaxim of the maxim of quantity ('make your contribution as informative as is required (for the current purposes of the exchange)') would be violated if just the propositional meaning of an answer like (12) were taken into account. However, the violation of the first submaxim of quantity is allowed in order to avoid violating the third submaxim of manner ('be brief'). In other words, a typical answer to (11) has the shape of (12) so as to avoid having to give an explicit and complete answer like (14), which is improper:

\# Nagore drank wine and the rest of the people did not.

The 'negative' part of information that is necessary as a complement of the propositional meaning of the answer in (12) in order to obtain an exhaustive or complete answer (namely, that the rest of the people in the relevant universe of participants did not drink wine) is left implicit for the hearer to infer. The complete answer is thus obtained by a conventional implicature, associated to the typical ENF intonation (nuclear accent on the subject followed by postfocal pitch compression). This implicature is such that the other potential candidates to fill the variable in the question (the members of the focus alternative set in Roothian terms, cf. section 5) are cancelled as potential values for the variable. This is, we suggest, the normal course of events in question-answer pairs.

Nevertheless, there are also other cases where we might cancel overtly and explicitly the completeness implicature brought by an answer, and these are the cases of NENF we will analyze. For instance, let us look at the question-answer pair in (15)-(16), repeated from (11)-(12):

Who drank wine?

(16) Nagore drank wine.

The answer in (16) can be uttered in two different ways intonationally. The first possibility is that it expresses ENF on the subject, in which the subject Nagorek exhausts the variable introduced by the wh-phrase who. The interpretation of this utterance would proceed along the path of the calculation of propositional meaning and conventional implicature outlined above. However, the sentence that constitutes the answer in (16) could represent another type of answer, one in which the subject Nagorek does not provide an exhaustive answer. In contrast to the answer with ENF on the subject, the speaker might want to express that, as far as (s)he knows, Nagore drank wine, but (s)he cannot commit herself to saying that only Nagore and nobody else drank wine. (S)he is not in a position to 
cancel the rest of the alternatives, and hence (s)he cannot provide a complete answer). In other words, the speaker wants to convey the meaning that other people may or may not have drunk wine, too (otherwise, (s)he would be violating the $2^{\text {nd }}$ submaxim of quality). We believe that this information is conveyed through a special type of intonation contour, different from the one of ENF and which we will describe in section 4 taking Northern Bizkaian Basque as a case study. This type of intonation contour may differ from one language to another, but in Northern Bizkaian Basque (and in French and Spanish, cf. Elordieta and Irurtzun in prep.) it involves the presence of a pitch accent on the verb, which is absent in ENF, and for some speakers, a continuation rise or peak delay in the accent on the subject. This type of answer constitutes an instance of NENF on the subject and this type of construction is the one we explore in this paper.

For the sake of clarity, let us illustrate a case of NENF with another example, just for clarification. Let us assume that we are in a classroom situation where we assigned the students some homework. If one asks the question in (17), a given student who finished her homework but does not know whether her fellows did can answer (18) truthfully, with the intonation contour used to signal NENF (which in English would involve a higher pitch on the auxiliary than in ENF). In such a situation, it is clear that there is no commitment for the completeness of the answer.

Who finished the homework?

I did.

As we pointed out in the introductory section, the concept of NENF has been around in the generative literature on focus, but it has received very scarce attention ${ }^{2}$. On our part, we had observed impressionistically that ENF and NENF could be distinguished intonationally in our native languages (Basque and Spanish) and the neighboring language French. In particular, we noticed clear differences for subject $w h$-questions such as (15)-(16) above, through a pitch accent on the verb (absent in ENF), and for some speakers, a continuation rise or peak delay in the accent on the subject. In order to test the veracity of our observation, we designed an experiment so as to analyze the intonational differences between both types of answers (ENF and NENF). This experiment is reported in section 3 .

\section{Methodology}

In order to assess empirically the differences and similarities in intonational contours between ENF, NENF and VF in Northern Bizkaian Basque, we designed a production experiment consisting of sets of questions and answers with different information structure. The utterances conveying ENF and NENF on the subject were answers to wh-questions of a hypothetical interlocutor, which would trigger the intended information structure. The VF utterances were statements reacting to a preceding statement by a hypothetical interlocutor. In order to achieve complete comparability, the answers expressing ENF, NENF and VF were identical at the written level, that is, they contained exactly the same words in the same word order. This would guarantee that only prosody and intonation would be responsible for expressing the difference, if any. The pairs of sentences in (19)(21) constitute examples of our stimuli (the rest of the question-answer pairs illustrating ENF, NENF and VF are included in the appendix). The answer in (19B) represents ENF on the subject, the answer in (20B) expresses NENF on the subject, and the answer in (21B) expresses VF. ${ }^{3}$

(19) [ENF on subject, Nagore]

$$
\begin{aligned}
& \text { A: Nok eran dau ardaua? } \\
& \text { who.eRG drink AUX wine.ABS }
\end{aligned}
$$

\footnotetext{
${ }^{2}$ For instance, Wollermann and Schröder (2009) try to describe possible intonational differences between exhaustive and non-exhaustive answers in German. In this study, the authors observe a tendency for non-exhaustive answers to exhibit higher pitch than exhaustive answers, through a higher frequency of occurrence of $\mathrm{H}^{*}$ and $\mathrm{H}-$.

${ }^{3}$ Basque is a discourse-configurational language. The basic, neutral or unmarked word order (as in broad focus declaratives) is SOV, but focalized constituents (as well as wh-phrases) appear in the immediately preverbal position. That is, sentences with focus on the subject have to have the word order SVO (or OSV, via a topicalization of the object). SVO is, as well, the word order employed to convey verum focus as in the example in (21).
} 
'Who has drunk wine?'

B: Nagorek eran dau ardaua.

Nagore.ERG drink AUX wine.ABS

'Nagore has drunk wine.'

(20) [NENF on subject, Nagore]

A: Nok eran dau ardaua?

Who.ERG drink AUX wine.ABS

'Who has drunk wine?'

\author{
B: Nagorek eran dau ardaua (nik dakitxela, baiña beste batzuk be igual edan dabe \\ ardaua) \\ Nagore.ERG drink AUX wine.ABS \\ 'Nagore has drunk wine (as far as I know, but other people may also have drunk wine)'
}

(21) $[\mathrm{VF}]$

A: Nagorek ardaua erango ebala esan eban, baiña ez dakitx eran badau.

Nagore.ERG wine.ABS drink.FUT AUX-C say AUX but NEG know drink AUX

'Nagore said she would drink wine, but I don't know if she has'

B: Nagorek eran dau ardaua.

Nagore.ERG drink AUX wine.ABS

'Nagore has drunk wine'.

We designed seven question-answer pairs for each type of focus. The subjects of our experiment were presented with the dialogues in separate blocks. The interviewer (one of the authors) read the questions or statements triggering the answer, and the subjects had to read the answers in as natural a style as possible. We had previously prepared the subjects for NENF by telling them about the difference in meaning with ENF. Since the question-answer pairs are identical for ENF and NENF, when we wanted speakers to produce NENF answers we told them that after that question they had to answer in a manner that could be interpreted by the listener as containing a message like "as far as I know", or "but other people may have drunk wine as well", for the specific case of (20B). In order to avoid artificially increased or decreased levels of prominence, we did not highlight or mark the constituents bearing narrow focus in any sense.

There were three repetitions of this scheme, per subject. Seven native speakers of Northern Bizkaian Basque were recorded, two male and five female, between the ages of 19 and 44 years old. In total, 441 utterances were recorded (3 focus types x 7 target sentences $\times 3$ repetitions $\times 7$ speakers). Eleven utterances were discarded because they contained mistakes or disfluencies, making a total of 430 sentences analysed.

In order to confirm the observation that an accent is present in the verb in subject NENF, we measured the peaks or F0 maxima (in $\mathrm{Hz}$ ) of the accents in the subject and the verb for all utterances. In all verb accents and in most cases of subject accents the peaks are aligned with the accented syllable (cf. sections 4.1-4.3 for more details and sample F0 contours), but in a few instances the subject did not show an accentual peak within the accented syllable (which was the penultimate syllable in all words) or in the postaccentual one (i.e., the final syllable). Rather, the pitch level continued rising throughout the final syllable, ending in a peak at the end of the word. We considered that $\mathrm{H}$ tone as a peak in the subject as well, given the absence of an earlier peak and the fact that this tone was only one syllable away. We will present the actual percentages of occurrence of these patterns in section $4.4 .^{4}$

\footnotetext{
${ }^{4}$ No comparison was made between the three types of narrow focus sentences with broad focus sentences, because the word order is different between broad and narrow focus: as already specified in footnote 2, the word order in broad
} 
Directly related to the measurements of peaks in the accented syllables in subjects and verbs, we wanted to see whether the F0 falls from the peaks in the subjects to the peaks in the verbs would differ significantly across the three focus contexts. That is, the question was whether differences in degree of downstep between the two accents (in the subject and in the verb) would correlate with different types of focus types. For that, we measured the difference in pitch level between those peaks within the same utterance across the three narrow focus types.

\section{Results}

First of all, let us show representative F0 contours of ENF, NENF and VF sentences, respectively. The utterances chosen are all renditions of sentences (19)-(21) presented above. For ease of reference, the subject and the verb are segmented in syllables. In the legends under each F0 contour, the accented syllables (i.e., the syllables bearing a pitch accent) are presented in boldface.

\subsection{Exhaustive Narrow Focus (ENF) on the subject}

\section{[FIGURE 1 HERE]}

As can be observed in Figure 1, uttered by Speaker LG, the accented syllable in the subject (i.e., go) displays the most prominent accent in the utterance, which in the variety of Northern Bizkaian Basque spoken by this speaker (that of the town of Lekeitio) is assigned to the penultimate or final syllable, depending on whether the word is lexically accented or not, respectively. In Northern Bizkaian Basque, words can be lexically accented or lexically unaccented, as in Tokyo Japanese (cf. Beckman 1986, Pierrehumbert and Beckman 1988, Haraguchi 1991, Kubozono 1993, among others, for Tokyo Japanese; cf. Hualde 1989, 1999, Hualde, Elordieta and Elordieta 1994, Elordieta 1997, 1998, 2003, Jun and Elordieta 1997, among others, for Northern Bizkaian Basque). The pitch accent is realized as a fall from a high tone on the accented syllable to the end of the word, and is characterized as $\mathrm{H}^{*}+\mathrm{L}$ in Autosegmental-Metrical terminology by Hualde et al. 1994, Elordieta 1997, 1998, Jun and Elordieta 1997, among others). The subject Nagorek 'Nagore (erg.)' is a lexically accented word and thus gets penultimate stress. Participial verbs in almost all local varieties of Northern Bizkaian Basque are not lexically accented, and only get an accent if they are focalized or a future participle or an imperfective participle is added to them, which is not the case of the verb eran, in the utterance in Figure 1 (cf. the above references for Northern Bizkaian Basque). That is why no pitch accent is marked on the participial verb. Only when it is focalized does the participial verb present a pitch accent. ${ }^{5}$ Auxiliaries are not lexically accented either unless they contain the morpheme for second and third person plural subjects, $-e$, which is not the case of the auxiliary dau in the utterance in Figure 1. Hence, no pitch accent is marked for the auxiliary, either.

In cases of ENF on the subject, the pitch range is compressed substantially after the focalized subject, as can be observed in Figure 1. The material following the subject is pronounced in a narrow pitch range, and presents a low or descending intonational contour until the end of the utterance. The compression of the pitch range after the focalized subject is responsible for such low F0 values in the periphrastic verb. In fact, no pitch accent and hence no F0 peak can be perceived in the verb in ENF. However, in order to be able to compare values of F0 maxima in the participial verbs across focus types, we measured the highest F0 value in the participial verb in ENF and took that value for the purposes of the comparison with the values in NENF and VF.

The postverbal object ardaue is a lexically unaccented word, and lexically unaccented words will not get an accent unless they appear immediately preceding the verb or are uttered in isolation (cf. the above references for Northern Bizkaian Basque). That is why no pitch accent is marked for

focus is SOV, whereas in narrow focus it is SVO.

${ }^{5}$ Unlike in the other NBB varieties, in the town of Ondarroa (where one of our speakers was from) the participial verb does get an accent on the final syllable in broad focus and non-verbal narrow focus as well. The difference between verbal accents in the different focus contexts is not one of presence vs. absence of an accent but one of scaling instead: the peaks are higher in NENF or VF than in ENF. 
the object ardaue 'wine'. ${ }^{6}$

\subsection{Non-Exhaustive Narrow Focus (NENF) on the subject}

In cases of NENF on the subject, the general pattern observed is one in which the participial verb displays a pitch accent, unlike in ENF. Figure 2 is an illustrative example of a NENF utterance in Northern Bizkaian Basque, by Speaker AE. There, the pitch contour of the participial verb edan is substantially different from the comparable ENF utterance in Figure 1. ${ }^{7}$ Unlike the descending movement in the participial verb in Figure 1, in Figure 2 the trajectory that the pitch curve follows in edan changes from a descending movement after the subject to a rising movement on the accented syllable, dan. This is an unmistakable sign of the presence of a pitch accent on the participial verb, that is, of a $\mathrm{H}^{*}+\mathrm{L}$ pitch accent. The $\mathrm{H}^{*}$ tone is responsible for the rise in pitch on the second syllable of the participial verb, the accented syllable. Thus, the pitch level of the participial verb is higher than in ENF, although still downstepped with respect to the one in the subject. The interesting aspect of the presence of this pitch accent is that it appears on a word (the participial verb) that, as explained in the previous subsection, does not bear a lexical pitch accent. Participial verbs without lexically accented morphemes, such as edan, can only receive a pitch accent if they are focalized. But the participial verb in a sentence such as (20b) should not be the narrow focus of the utterance, given that the previous question bears such a load on the subject. This is a crucial difference with ENF that we will discuss in section 5.

\section{[FIGURE 2 HERE]}

\subsection{Verum Focus (VF)}

Figure 3 illustrates a case of VF. In these constructions, the polarity of the event is the focus of the sentence, and is intonationally realized on the participial verb, through a pitch accent. The subject also displays a pitch accent, and the pitch accent on the verb appears downstepped with respect to it.

\section{[FIGURE 3 HERE]}

\subsection{A comparison of subject and verb peak heights in ENF, NENF and VF}

We start our presentation of the quantitative results with the comparison of F0 maxima (i.e., accentual peaks) in the accented syllable of the verb, because it is in the verb where the main differences are found. In the previous subsections we showed that the verb does not display an accent in ENF but it does in NENF and VF.

\subsubsection{Scaling of F0 maxima in the verb}

Table 1 shows the mean F0 maximum (in Hz) in the accented syllable in the verb across the three focus types. It can be seen that ENF has the lowest values, followed by NENF and VF, in ascending order, thus confirming our initial observations and hypothesis.

\begin{tabular}{|l|c|c|c|}
\hline & ENF & NENF & VF \\
\hline $\begin{array}{l}\text { F0 max in the accented } \\
\text { syllable in the verb }(\mathrm{Hz})\end{array}$ & 172.92 & 199.43 & 207.56 \\
$(\mathrm{~N}=147 ; \mathrm{SE}=3.62)$ & $(\mathrm{N}=138 ; \mathrm{SE}=5.04)$ & $(\mathrm{N}=145 ; \mathrm{SE}=5.21)$ \\
\hline
\end{tabular}

Table 1. Mean values of $\mathrm{F} 0$ maxima (in $\mathrm{Hz}$ ) in the accented syllable in the verb across the three narrow focus conditions: ENF, NENF and VF

A one-way ANOVA with Focus Type as a factor with three levels (ENF, NENF and VF, post hoc Tukey test) revealed a statistically significant effect of Focus Type on the scaling patterns of F0

\footnotetext{
${ }^{6}$ The form ardaue in this sentence corresponds to the local variety of the speaker pronouncing this utterance, Speaker LG. It is an alternant of the form ardaua in examples (19)-(21) and of the form ardau in the example in Figure 3, corresponding to the local variety of Speaker AA. The three forms are local variants of the same word in NBB.

${ }^{7}$ The form edan in this utterance is faithful to the underlying phonological form of the verb. The form eran in Figure 1 (and Figure 3 below) is an alternant in which the intervocalic /d/ is rhotacized, a common phenomenon in Basque.
} 
maxima in the stressed syllable in the verb $(\mathrm{F}(2,427)=15.349, \mathrm{p}<.001)$. The differences are statistically significant between ENF and NENF and between ENF and VF (both at $p<.001$ ), but not between NENF and VF. The graph in Figure 4 illustrates the levels of F0 maxima in stressed syllables in the verb. The values are in $\mathrm{Hz}$.

\section{[FIGURE 4 HERE]}

Converted to semitones, NENF and VF verbal peaks are 2.5 st and 3.2 st higher than ENF ones, respectively. Those are substantial differences, highly perceivable. VF peaks are only $0.7 \mathrm{st}$ higher than NENF ones. The results thus show that F0 maxima in the periphrastic verb's stressed syllable are significantly higher in NENF or VF than in ENF. As already pointed out above, this contrast is expected for the comparison ENF-VF, as the verb is focalized in VF, but not for the comparison ENF-NENF, given that the triggering wh-question does not set the verb as narrow focus, but the subject. In principle, in both cases the verb would constitute given information, as the answer contains the verb repeated from the question. This is an issue we discuss in section 5.

There was a significant interaction between the factors 'Focus Type' and 'Speaker', $(\mathrm{F}=30.636, \mathrm{p}<.001)$. Speaker AA does not show a significant difference between ENF and NENF. This is probably due to the fact that in the local variety of this speaker (Ondarroa) the verb shows a pitch accent in ENF, unlike in the other varieties (cf. fn 4). For four speakers, the difference between NENF and VF proved significant; the F0 maximum or peak in the verbal accent was significantly higher in VF than in NENF.

\subsubsection{Subject peak heights}

Table 2 shows the mean $\mathrm{F} 0$ maximum (in $\mathrm{Hz}$ ) in the accented syllable in the subject across the three focus types. The values for ENF and VF are very similar, and the ones for NENF are the highest.

\begin{tabular}{|l|c|c|c|}
\hline & ENF & NENF & VF \\
\hline $\begin{array}{l}\text { F0 max in the accented } \\
\text { syllable in the subject } \\
(\mathrm{Hz})\end{array}$ & 226.56 & 236.37 & 228.91 \\
$(\mathrm{~N}=147 ; \mathrm{SE}=4.58)$ & $(\mathrm{N}=138 ; \mathrm{SE}=5.22)$ & $(\mathrm{N}=145 ; \mathrm{SE}=4.83)$ \\
\hline
\end{tabular}

Table 2. Mean values of F0 maxima (in $\mathrm{Hz}$ ) in the accented syllable in the subject across the three narrow focus conditions: ENF, NENF and VF

A one-way ANOVA with a post hoc Tukey test showed that the differences between these values are not statistically significant. In semitones, the differences between the F0 maxima in NENF on the one hand and ENF and VF on the other are of only 0.7 and 0.6 st, respectively.

The graph in Figure 5 illustrates the levels of F0 maxima in stressed syllables in the subject, followed by the F0 maxima values in the verb, from Figure 4. That way the relative scaling of peaks in the stressed syllables in the subject and the verb in the three focus conditions can be represented schematically as in an utterance.

\section{[FIGURE 5 HERE]}

There was a significant interaction between the factors 'Focus Type' and 'Speaker', $(\mathrm{F}=11.357, \mathrm{p}<.001)$. For three of the seven speakers, F0 maxima in the subject's accented syllable were significantly higher in NENF than in ENF and VF. A fourth one showed significant differences only between NENF and ENF.

\footnotetext{
${ }^{8}$ One factor contributing to the higher F0 value in the subject in NENF may be the continuation rise occurring at the right edge of subjects in some instances of NENF. For two speakers, this was observable in $90.47 \%$ and $80.95 \%$ of their NENF utterances. The F0 maximum at the end of the subject was taken as the F0 maximum of the accented syllable in the subject, for the reasons stated in section 3, namely the absence of an earlier peak and the fact that this tone was only one syllable away.
} 


\subsubsection{Differences between subject peak and verb peak}

A clear cue distinguishing the different focus types could be the difference in F0 maxima between the subject and verb accentual peaks within each utterance, that is, the F0 falls from the peaks in the subjects to the peaks in the verbs. The graph in Figure 5 is a good indicator of such contrasts. The fall in ENF appears to be bigger than the one for NENF and especially VF. The mean differences (in $\mathrm{Hz}$ ) are the following:

\begin{tabular}{|c|c|c|c|}
\hline & ENF & NENF & $\mathrm{VF}$ \\
\hline $\begin{array}{l}\text { Difference in } \mathrm{Hz} \\
\text { between F0 max in the } \\
\text { subject and F0 max in } \\
\text { the verb }(\mathrm{Hz})\end{array}$ & $\begin{array}{c}53.64 \\
(\mathrm{~N}=147 ; \mathrm{SE}=1.39)\end{array}$ & $\begin{array}{c}36.93 \\
(\mathrm{~N}=138 ; \mathrm{SE}=1.60)\end{array}$ & $\begin{array}{c}21.35 \\
(\mathrm{~N}=145 ; \mathrm{SE}=1.73)\end{array}$ \\
\hline
\end{tabular}

Table 3. Mean F0 falls (in Hz) between F0 maxima in the subject's stressed syllable and F0 maxima in the verb's stressed syllable across the three narrow focus conditions: ENF, NENF and VF

In semitones, the fall in ENF is one of $4.7 \mathrm{st}$; in NENF, it is $2.9 \mathrm{st}$; and in_VF, it is $1.7 \mathrm{st}$. So the falls in ENF are 1.8 st higher than in NENF and 3 st higher than in VF. The falls in NENF are 1.2 st higher than in VF. A one-way ANOVA with a post hoc Tukey test revealed significant differences between the three conditions, all at $\mathrm{p}<.001(\mathrm{~F}(2,427)=105.648, \mathrm{p}<.001){ }^{9}$

To sum up the results of the experiment, ENF is unambiguously distinguished from NENF intonationally, through differences in the scaling of the peaks or F0 maxima in the stressed syllable of the participial verb. The participial verb in ENF is in the postfocal region, with a depressed pitch range, and there is virtually no pitch accent on it. ${ }^{10}$ In NENF, on the other hand, there is a clear pitch accent on the participial verb, and thus the F0 level is higher in NENF than in ENF. ENF and VF are also distinguished in the verb along the same lines. This is expected, since in VF the verb is focalized. What is not expected is the F0 height in the verb in NENF, since the triggering question does not set narrow focus on the verb, but on the subject. ENF and NENF are less clearly distinguished in the subject. The F0 maxima in the subject's stressed syllable are higher in NENF than in ENF, although only significantly so for three of the seven speakers. As a consequence of the significantly higher F0 maximum value in the participial verb in NENF, the degree of downstep or of F0 falls from the subject's highest F0 point to the verb's highest F0 point are also significantly different in ENF and NENF, being much bigger in ENF than in NENF.

Another important result is that NENF and VF do not appear to differ significantly in their scaling patterns for the peaks of the accented syllables in the subject and the verb. The average F0 maximum in the verb is higher in VF than in NENF, but only significantly so for three speakers. On the other hand, the average F0 maximum in the subject's accent is higher in NENF than in VF, but only significantly so for three speakers. Of these three speakers, only two have significant differences both in the subject and the verb. We will discuss these results in the next section.

\section{Discussion and analysis}

We saw so far that the main prosodic difference between ENF and NENF is that in NENF there is an 'extra' pitch accent on the polarity-bearing verb, one that is not expected by the question. On the other hand, the semantic difference between ENF and NENF is the following: in an ENF answer to a preceding subject $w h$-question like (19A), the constituent in the subject fills the variable of the question exhaustively. The rest of the focal alternatives are cancelled by a conventional implicature associated to the ENF intonational contour, as explained in section 2. In NENF, on the other hand, speakers convey the meaning that they cannot provide an exhaustive answer for the question that calls for narrow focus on the subject. That is, they express the meaning that the constituent they

\footnotetext{
${ }^{9}$ Two of the speakers did not show a statistically significant difference between NENF and VF, and two others did not show a statistically significant difference between ENF and NENF.

10 With the exception of the local speech in the town of Ondarroa, represented by one of the speakers.
} 
provide in the answer is not necessarily the only one satisfying the property expressed by the question, as they cannot commit to asserting that the other alternatives are cancelled.

Our proposal for formalizing the semantic difference between ENF and NENF is couched in the framework of Alternative Semantics of Rooth $(1985,1992)$. According to this approach, a focused phrase brings about two types of meanings: an Ordinary Semantic Value (which is the standard denotation of the phrase) and a Focus Semantic Value, which is obtained with a substitution of the phrase with alternative values that match it in semantic type. Thus, in an ENF sentence, the constituent in subject position (e.g. Nagore) is associated to the property described by the question (i.e., the 'open proposition' that someone drank wine). The rest of the alternatives raised by the focal feature on the subject (Jon, Kepa, etc.) are cancelled as potential satisfiers of that property via the aforementioned conventional implicature that provides the complete answer. This is shown in (22), as a representation of the semantics of the ENF answer in (19B):

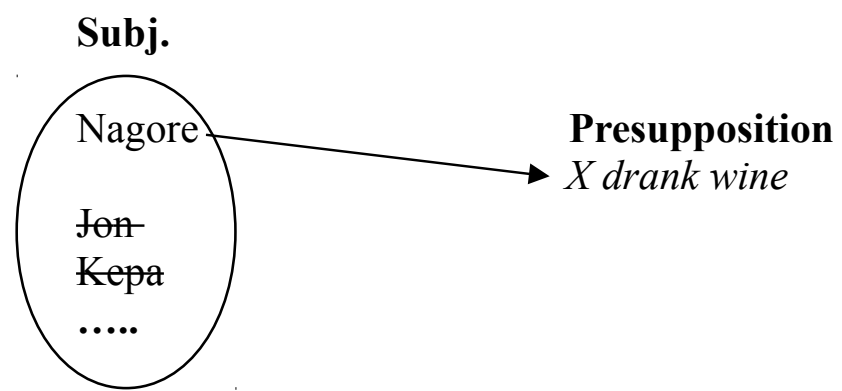

In NENF, on the other hand, speakers only commit to asserting that the subject satisfies the property described by the question, in fact, they actually express that they are not in a situation to clarify whether all other alternative values also do.

Now, the question is: how is this expressed overtly in grammar? As (19)-(20) show, ENF and NENF answers have the same words and the same word order. So they are homophonous at the segmental level. Our claim is that prosody disambiguates the two types of constructions. ENF is conveyed by main prosodic prominence on the constituent that answers for the variable in the question followed by a reduction in pitch range. NENF is conveyed by prosodic prominence on the subject but without reduction or compression of pitch range in the following region. Actually, the participial verb (which expresses the event of the sentence) appears with a clear pitch accent, as the results of the experiment have revealed. In fact, the pitch value obtained on the verb in NENF utterances is similar to the one observed in VF constructions, where the polarity of the event denoted by the verb is the narrow focus of the utterance. We would like to propose that the F0 peak that we observe in the verb in NENF utterances is a prosodic correlate of having an extra focal feature in the polarity in these constructions. We also claim that in NENF utterances like (20B) we have a split focus construction where neither the subject nor the polarity marker is the focus of the sentence but rather the pair $<$ Subject, polarity $>$ is. ${ }^{11}$

Our idea is that having this extra focal feature brings about alternative values not only in the subject, but also in the polarity, whose alternative values are the positive polarity and negative polarity ('yes/no', for short). Thus, for a question like (19A) or (20A), in a NENF answer like (20B) a speaker only asserts that Nagore drank wine. This is obtained by having a focal feature in the subject (raising the alternative values just as in (22)) but also by a second focal feature on the polarity marker, which raises its alternative value (i.e., no). In a NENF sentence like (20B) we assert that Nagore is associated with the positive polarity, but having alternative values for both subjects and polarities brings about the question as to how to pair the rest of them, and we propose that in NENF it is precisely the openness of the other pairings that is being conveyed. That is, in a NENF sentence we assert that the phrase that substitutes the variable in the question is paired with the polarity expressed by the verb (i.e., $<$ Nagore, yes $>$ ), but we do not close other potential pairs

\footnotetext{
11 See Irurtzun (2007) for an analysis of answers to multiple-wh questions as split foci.
} 
(e.g., $<$ Jon, yes/no $>$, $<$ Kepa, yes/no $>$, $<$ Itziar, yes/no $>,<$ Amaia, yes/no $>$, etc). This is represented in the Venn-diagrams in (23):

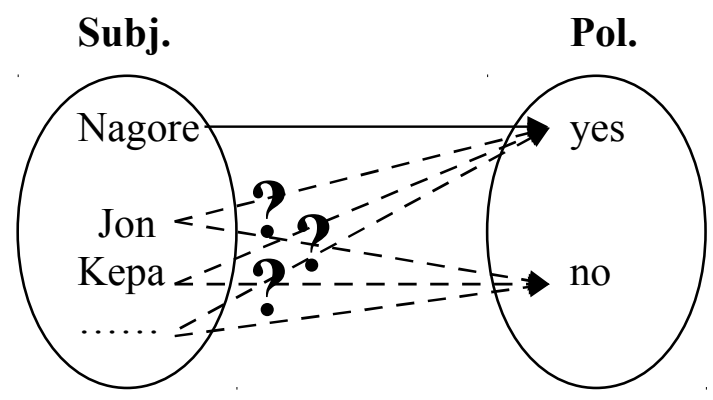

Thus, our idea is that these split focus constructions create NENF readings when we compute the alternative values for both subjects and polarities. NENF constructions then share having a focal subject with ENF constructions and having a focal polarity with VF constructions. The focal polarity is responsible for the presence of a pitch accent on the verb, just like in VF. This would explain the absence of significant differences in peak scaling in the verb's pitch accent in NENF and VF. As a result of their split focus nature and their intonational properties, NENF constructions are not associated to the implicature of completeness of ENF constructions.

Thus, our idea is that these split focus constructions create NENF readings when we compute the alternative values for both subjects and polarities. In these constructions the implicature of completeness would not arise.

Moreover, we can bring forth morphosyntactic evidence in support of the view that NENF answers are split foci of the <Subject, Polarity> sort. In Basque there are two types of verbs: synthetic verbs, where the verbal root appears sandwiched within inflectional morphology (aspectual and temporal markers, as well as agreement morphology), and periphrastic verbs, which show a lexical verb with aspectual markers and a separate auxiliary verb with temporal and agreement morphology. There are some verbs that can only appear in one of the two forms, but there are also some verbs that allow both synthetic and periphrastic forms. One such verb is the verb ekarri 'to bring'. See for example the verbal forms in $(24 a-b)$ :

a. dakart

bring.1sgERG.3sgAbs.PRES

'I bring it' b. ekartzen dut

bring.ImPF Aux.1sgErg.3sgAbs.Pres

'I bring it'

Now, there is a positive polarity particle $b a$ - (cf. bai 'yes') which is required in VF constructions with synthetic verbs. Syntactically, it sits in a higher functional projection (cf. Laka's $1990 \Sigma \mathrm{P}$ ) and procliticizes to synthetic verbs. This can be observed in (26a), as an answer to (25). The lack of this particle in verum focus constructions with synthetic verbs brings about ungrammaticality, as shown in (26b):

Azkenean, Jonek ekarriko al du ardoa?

'In the end, will Jon bring the wine?'

a. Bai, ba-dakar.

yes BA-bring.3sgERG.3sgABs.PRES

'Yes, he is bringing it'

(lit., 'Yes, he does bring it.') b. *Bai, dakar.

yes bring.3sgERG.3sgAbs.PRES

'Yes, he is bringing it'

(lit., 'Yes, he does bring it.')

Our analysis of NENF explained above is that this type of narrow focus introduces a focal feature on the polarity of the event, expressed by the verb. Thus, both NENF and VF present focus on the verb (paired with focus on the subject, in NENF). The prediction would thus be that NENF 
constructions with synthetic verbs will require the particle $b a$-. This prediction is borne out: the proclitic particle $b a$ - is also mandatory in NENF sentences. Thus, a subject $w h$-question with a synthetic verb like jakin 'to know' in (27) (which appears inflected as daki) can receive an ENF or a NENF answer. The ENF answer appears without the particle $b a$ - (cf. (28b)), and the NENF answer needs to have the particle $b a$-attached to the synthetic verb (cf. (28a)).

\title{
Nork daki errusiera?
}

'Who knows Russian?'

\author{
a. Nik ba-dakit. \\ I BA-know.1sgERg.3sgABs.PRES \\ 'I do' (lit., 'I know')
}
b. Nik dakit. ${ }^{12}$
I know.1sgERg.3sgABs.PRES
'I do' (lit., 'I know')

Returning to our discussion, the interesting theoretical question that arises is whether ENF and NENF are two distinct types of narrow focus constructions, that is, two types of categories of information structure. Given the difference in meaning conveyed by the two types of constructions and the different prosodic patterns that serve to convey them, it would have to be concluded that indeed they are two types of narrow focus constructions. However, this does not imply that ENF and NENF are different grammatical primitives, given that NENF constructions would be nothing more than split foci. If what we are suggesting proves correct, it will have the interest and relevance of putting light on a hitherto unstudied type of narrow focus construction whose main characteristic is being a split focus composed by the phrase that stands for the wh-phrase and the polarity marker.

However, it is nonetheless also true that the results obtained from our experiment did not reveal significant intonational differences between NENF and VF constructions. The accentual peak height values in the subject and the verb were not significantly different between the two types of constructions. The average F0 maximum in the verb is higher in VF than in NENF, but only significantly so for three speakers. On the other hand, the average F0 maximum in the subject's accent is higher in NENF than in VF, but only significantly so for three speakers. Of these three speakers, only two have significant differences both in the subject and the verb. All these findings corroborate our departure intuition that NENF and VF constructions sound quite alike. So, given these results, would we have to conclude that NENF and VF are not intonationally distinct categories, in Northern Bizkaian Basque at least? Or that they are distinct categories but we have not managed to find yet where the differences lie? Or perhaps the differences between NENF and VF are gradient rather than categorical? These are interesting questions, for which we have no answer at the moment. It seems clear that perception experiments would be relevant in order to elucidate how categorical or gradient these contrasts or distinctions between ENF, NENF and VF are. We plan to undertake such a task in future research.

\section{Issues for further research}

We would like to end this section by bringing to discussion a study that, although not exactly comparable to ours, can provide interesting information on the issue of non-exhaustiveness and the insertion of (non-required) pitch accents. Marandin, Beyssade, Delais-Roussarie and Rialland (2002) analyze the prosodic patterns that we can observe in French in partial answers of the following type (ex. 5 of Marandin et al. 2002):

Que fumaient les chanteurs de rock?

what smoke ART. singers of rock

'What did the rock singers smoke?'

\footnotetext{
${ }^{12}$ In some dialects of Basque, focalized pronouns adopt the so-called intensive form (cf. Trask 2003: 152-4). In the case of (28b), the intensive form of the subject pronoun bearing ENF would be neuk. Interestingly, the pronoun in the NENF case (28a) cannot appear in the intensive form and has to appear in the ordinary, non-intensive form. The conclusion would thus be that the intensive forms are restricted to ENF. This would be another non-prosodic difference between ENF and NENF.
} 
(30) a. Les chanteurs de rock ANglais fumaient des cigarettes. ART. singers of rock English smoke PART. cigarettes

'The English rock singers smoked cigarettes'

a'. Les CHANteurs de rock anglais fumaient des cigarettes.

a". Les CHANteurs de rock ANglais fumaient des cigarettes.

b. \#Les chanteurs de rock anglais fumaient des cigarettes.

The question in (29) demands filling the variable of the direct object, but the answers in (30a-a") do more than fulfilling that demand; they fill the variable with des cigarettes and they also add a specification for the subject (singling out the English singers). This way, the answer takes a partial reading, because it does not provide an answer that covers all singers. Marandin et al. (2002) argue that in order to provide a partial reading, any of the patterns of (30a-a") are possible: either a pitch accent on the first syllable of the adjective anglais, as in (30a); a pitch accent on the head of the NP chanteurs, as in (30a'); or even a pitch accent on both chanteurs and anglais (30a"). The pitch accent that appears in these contrastive topic-like constructions is characterized by a sharp rise in F0, a lengthening of the onset of the accented syllable, and a rise of intensity. Marandin et al. (2002) call it a ' $\mathrm{C}$ accent' ${ }^{13}$. But as shown in (30b), sentences without an accent on a word in the subject are ungrammatical if a partial answer is to be provided. Thus, it seems that a pitch accent is mandatory on a constituent introducing a selection of alternatives (i.e., contrast or focus), despite not being called for by a preceding question. This aspect of the question-answer pairs studied by Marandin et al. (2002) shares certain similarities with the NENF constructions analyzed in this paper, in the sense that in both contexts we add a pitch accent that was not required by the question under discussion. Both constructions would be instances of split foci.

Despite the similarities between the type of constructions analyzed by Marandin et al. (2002) and the NENF constructions analyzed in the present article, it is also important to point out that they are not completely equivalent. The data in Marandin et al. (2002) concern questions on the direct object, and the added tonal specification on the subject (the $\mathrm{C}$ accent) is a prenuclear accent. In the data we have analyzed, however, the subjects are the expected foci of the sentences; the answer sentences they appear in are answers to questions over the subject. That is, they match the classical definition of semantic focus. On the other hand, the accent on the verb (on the polarity, more specifically) in NENF constructions is a nuclear accent (i.e., the final pitch accent of the utterance). Despite these differences, it would be interesting to carry out an analytical comparison of both types of constructions, in order to draw possible generalizations about explicit partial answers and the presence of pitch accents. We plan to undertake this task in future research.

\section{References}

Beckman, M., 1986, Stress and non-stress accent, Foris, Dordrecht.

Büring, D., 1999, “Topic”, in P. Bosch and R. van der Sandt (eds.), Focus: linguistic, cognitive, and computational perspectives, Cambridge University Press, Cambridge (UK), 142-165. , 2003, "On D-Trees, Beans, and B-Accents", Linguistics \& Philosophy 26:5, 511-545.

É. Kiss, K., 1998, “Identification focus versus information focus”, Language 74 : 245-273. 2002, The syntax of Hungarian, Cambridge University Press, Cambridge.

Elordieta, G., 1997, "Accent, tone, and intonation in Lekeitio Basque", in F. Martínez-Gil and A. Morales-Front (eds.), Issues in the phonology and morphology of the major Iberian languages, Georgetown University Press, Washington, D.C., 3-78.

, 1998, "Intonation in a pitch accent variety of Basque", International Journal of Basque Linguistics and Philology 32: 511-569.

\footnotetext{
13 See also Jackendoff (1972), Büring (1999, 2003), van Hoof (2003) and Gyuris (2009) for discussions on the interpretation of this type of utterances, as well as Skopeteas and Féry (2007) for a multilanguage analysis of similar data involving Greek, Georgian, German and English.
} 
, 2003, "Intonation", in J. I. Hualde and J. Ortiz de Urbina (eds.), A grammar of Basque, Mouton de Gruyter, Berlin and New York, 72-113.

, and A. Irurtzun, 2009, "Non-exhaustive answers to $w h$-questions as split foci", paper presented at the Workshop on Prosody and Meaning, Barcelona, September 17-18, 2009.

, and A. Irurtzun, in progress, "Similarities and differences in the expression of non-exhaustive answers: a comparative study of French, Basque, and Spanish", ms, UPV/EHU and UIB.

Grice, P., 1975, "Logic and conversation", in P. Cole and J.L. Morgan (eds.), Syntax and semantics vol. 3: Speech acts, Academic Press, New York, 41-58.

Groenendijk, J. and M. Stokhof, 1982, "Semantic analysis of wh-complements", Linguistics and Philosophy 5-2: 175-233.

Gyuris, B., 2009, "Quantificational Contrastive Topics with Verum/Falsum Focus", Lingua 119: 625-649.

Hamblin, C.L., 1973, “Questions in Montague English”, Foundations of Language 10: 41-53.

Haraguchi, S., 1991, A theory of stress and accent, Dordrecht: Foris.

Higginbotham, J., and R. May, 1981, "Questions, quantifiers and crossing”, The Linguistic Review 1: 41-80.

Horn, L.R., 2004, "Implicature", in L.R. Horn and G. Ward (eds.), The Handbook of pragmatics, Blackwell, Oxford, 3-28.

Horvath, J., 2010, "Discourse features, syntactic displacement and the status of contrast", Lingua $120,1346-1369$.

Hualde, J. I., 1989, “Acentos vizcaínos”, International Journal of Basque Linguistics and Philology 23: 275-325.

1999, "Basque accentuation", in H. van der Hulst (ed.), Word prosodic systems in the languages of Europe, Mouton de Gruyter, Berlin, 947-993.

, G. Elordieta, and A. Elordieta, 1994, The Basque dialect of Lekeitio, Servicio Editorial de la Universidad del País Vasco, Bilbao and San Sebastián.

Irurtzun, A., 2007, The Grammar of Focus at the Interfaces, PhD. dissertation, UPV/EHU.

Ito, K., G. Elordieta, and J. I. Hualde, 2003, "Peak alignment and intonational change in Basque", in M.-J. Solé, D. Recasens, and J. Romero (eds.), Proceedings of the 15th International Congress of Phonetic Sciences, Causal Productions Pty Ltd, Barcelona, 2929-2932.

Jackendoff, R., 1972, Semantic interpretation in generative grammar, MIT Press, Cambridge.

Jun, S.-A., and G. Elordieta, 1997, "Intonational structure of Lekeitio Basque", in A.Botinis, G. Kouroupetroglou, and G. Carayiannis (eds.), Intonation: Theory, models and applications, ISCA, Athens, 193-196.

Karttunen, L., 1977, "Syntax and semantics of questions", Linguistics and Philosophy 1: 3-44.

Kenesei, I., 2006, "Focus as identification", in V. Molnár and S. Winkler (eds.), The architecture of focus, Mouton de Gruyter, Berlin, 137-168.

Krifka, M., 1999, “At least some determiners aren't determiners”, in K. Turner (ed.), The Semantics/Pragmatics Interface from Different Points of View, Elsevier, Oxford, 257-291.

Kubozono, H., 1993, The organization of Japanese prosody. Kurosio, Tokyo.

Lahiri, U., 2002, Questions and answers in embedded contexts, Oxford University Press, Oxford.

Laka, I., 1990, Negation in syntax: On the nature of functional categories and projections, $\mathrm{PhD}$. Dissertation: MIT.

Marandin, J.M., C. Beyssade, E. Delais-Roussarie, and A. Rialland, 2002, "Discourse Marking in French: C Accents and Discourse Moves", in B. Bel and I. Marlien (eds.), Proceedings of Speech Prosody 2002, Aix-en-Provence, 471-474.

Molnár, V., 2006, "On different kinds of contrast", in V. Molnár and S. Winkler (eds.), The architecture of focus, Mouton de Gruyter, Berlin, 197-233.

Pierrehumbert, J., and M. Beckman, 1988, Japanese tone structure, MIT Press, Cambridge.

Rooth, M., 1985, Association with focus, PhD. dissertation: UMass.

Rooth, M., 1992, “A theory of Focus Interpretation”, Natural Language Semantics 1: 75-116.

Skopeteas, S., and C. Féry, 2007, "Contrastive topics in pairing answers: A cross-linguistic 
production study", in S. Featherston and W. Sternefeld (eds.), Roots: Linguistics in search of its evidential base, Mouton de Gruyter, Berlin, 319-340.

Spector, B., 2006, Aspects de la pragmatique des opérateurs logiques, PhD. dissertation, Université de Paris 7 - Denis Diderot.

Trask, R. L., 2003, “The Noun Phrase: nouns, determiners and modifiers; pronouns and names”, in J. I. Hualde and J. Ortiz de Urbina (eds.), A grammar of Basque, Mouton de Gruyter, Berlin and New York, 113-170.

Wollermann, C., and B. Schröder, 2009, "Effects of exhaustivity and uncertainty on audiovisual focus production", in Proceedings of International Conference on Auditory-Visual Speech Processing, Norwich, 145-150.

\section{Appendix: Types of utterances recorded}

\section{a) Exhaustive Narrow Focus on the subject}

Q1: Nok erun dau liburua? who.erg take AUX book.ABS

'Who took the book?'

A1: Ainarak erun dau liburua. Ainara.ERG take AUX book.ABS 'Ainara took the book.'

Q2: Nok eran dau ardaua? who.ERG drink AUX wine.ABS 'Who drunk wine?'

A2: Nagorek erandau ardaua. Nagore.ERG drink AUX wine.ABS 'Nagore drunk wine.'

Q3: Nok bialdu dotzos lorak Ainhoari? who.ERG send AUX flower.ABS.PL Ainhoa.DAT 'Who sent flowers to Ainhoa?'

A3: Mirarik bialdu dotzos lorak Ainhoari. Mirari.erg send AUX flower.ABS.PL Ainoa.DAT 'Mirari sent flowers to Ainhoa.'

Q4: Nok emon dotzo dirua Andoniri? who.erg give AUX money.ABS Andoni.DAT 'Who gave money to Andoni?'

A4: Amagoiak emon dotzo dirua Andoniri. Amagoia.erg give AUX money.ABS Andoni.DAT 'Amagoia gave money to Andoni'

Q5: Nok erregala dotzo andrakua umiari? who.ERG offer AUX doll.ABS child.DAT 'Who gave the doll to the child?'

A5: Begoñak erregala dotzo andrakua umiari Begoña.ERG offer AUX doll.ABS child.DAT 'Begoña gave the doll to the child'

Q6: Nok ebagidau bedarra? 
who.ERG cut AUX grass.ABS

'Who cut the grass?'

A6: Marianok ebagidau bedarra

Mariano.erg cut AUX grass.ABS

'Mariano cut the grass'

Q7: Nok eran dau limonadia?

who.ERG drink AUX lemonade.ABS

'Who drank the lemonade?'

A7: Amumak eran dau limonadia.

grandmother.ERG drink AUX lemonade.ABS

'The grandmother drank the lemonade'

\section{b) Non-Exhaustive Narrow Focus}

Q1: Nok erun dau liburua?

who.erg take AUX book.ABS

'Who took the book?'

A1: Ainarak erun dau liburua. Ainara.ERG take AUX book.ABS

'Ainara took the book.'

Q2: Nok eran dau ardaua?

who.ERG drink AUX wine.ABS

'Who drunk wine?'

A2: Nagorek erandau ardaua.

Nagore.ERG drink AUX wine.ABS

'Nagore drunk wine.'

Q3: Nok bialdu dotzos lorak Ainhoari? who.ERG send AUX flower.ABS.PL Ainhoa.DAT

'Who sent flowers to Ainhoa?'

A3: Mirarik bialdu dotzos lorak Ainhoari.

Mirari.erg send AUX flower.ABS.PL Ainoa.DAT

'Mirari sent flowers to Ainhoa.'

Q4: Nok emon dotzo dirua Andoniri?

who.erg give AUX money.ABS Andoni.DAT

'Who gave money to Andoni?'

A4: Amagoiak emon dotzo dirua Andoniri. Amagoia.erg give AUX money.ABS Andoni.DAT

'Amagoia gave money to Andoni'

Q5: Nok erregala dotzo andrakua umiari?

who.erg offer AUX doll.ABS child.DAT

'Who gave the doll to the child?'

A5: Begoñak erregala dotzo andrakua umiari

Begoña.ERG offer AUX doll.ABS child.DAT

'Begoña offered the doll to the child'

Q6: Nok ebagidau bedarra? 
who.ERG cut AUX grass.ABS

'Who cut the grass?'

A6: Marianok ebagi dau bedarra

Mariano.erg cut AUX grass.ABS

'Mariano cut the grass'

Q7: Nok eran dau limonadia?

who.ERG drink AUX lemonade.ABS

'Who drank the lemonade?'

A7: Amumak eran dau limonadia.

grandmother.ERG drink AUX lemonade.ABS

'The grandmother drank the lemonade'

\section{c) Verum Focus: Two assertions in a conversation}

A1: Ainarak liburua erungo ebala esan eban, baiña ez dakitx erun badau Ainara.ERG book.ABS take.FUT AUX-C say AUX but NEG know take AUX askanian.

finally

'Ainara said she would take the book, but I don't know if she has, finally'

B1: Ainarak erun dau liburua.

Ainara.ERG take AUx book.ABS

'Ainara has (indeed) taken the book.'

A2: Nagorek ardaua erango ebala esan eban, baiña ez dakitx eran badau Nagore.ERG wine.ABS drink.FUT AUX-C say AUX but NEG know drink AUX askanian.

finally

'Nagore said she would drink wine, but I don't know if she has, finally'

B2: Nagorek eran dau ardaua.

Nagore.ERG drink AUX wine.ABS

'Nagore has (indeed) drunk wine'.

A3: Mirarik lorak bialduko eutzalala Ainhoari esan eban,

Mirari.ERG flower.ABS.PL send.FUT AUX-C Ainhoa.DAT say AUX

baiña ez dakitx bialdu badotzos askanian.

but NEG know send AUX finally

'Mirari said she would send flowers to Ainhoa, but I don't know if she has, finally'

B3: Mirarik bialdu dotzos lorak Ainhoari.

Mirari.ERg send AUX flower.ABS.PL Ainoa.DAT

'Mirari has (indeed) sent flowers to Ainhoa.'

A4: Amagoiak Andoniri dirua emongo eutzala esan eban,

Amagoia.ERG Andoni.DAT money.ABS send.FUT AUX-C say AUX

baiña ez dakitx emon badotzo.

but NEG know send AUX

'Amagoia said she would give money to Andoni, but I don't know if she has, finally'

B4: Amagoiak emon dotzo dirua Andoniri.

Amagoia.ERG give AUX money.ABS Andoni.DAT

'Amagoia has (indeed) given money to Andoni' 
A5: Begoñak umiari andrakua erregalako eutzala esan eban,

Begoña.ERG child.DAT doll.ABS offer.FUT AUX-C say AUX

baiña ez dakitx erregala badotzo.

but NEG know offer AUX

'Begoña said she would give the doll to the child, but I don't know if she has, finally'

B5: Begoñak erregala dotzo andrakua umiari

Begoña.ERG offer AUX doll.ABS child.DAT

'Begoña has (indeed) given the doll to the child'

A6: Marianok bedarra ebagiko ebala esan eban,

Mariano.ERG grass.ABS cut.FUT AUX-C say AUX

baiña ez dakitx ebagi badau.

but NEG know offer AUX

'Mariano said he would cut the grass, but I don't know if he has, finally'

B6: Marianok ebagi dau bedarra

Mariano.ERG cut AUX grass.ABS

'Mariano has (indeed) cut the grass'

A7: Amumak limonadia erango ebala esan eban,

grandmother.ERG lemonade.ABS drink.FUT AUX-C say AUX

baiña ez dakitx eran badau.

but NEG know offer AUX

'The grandmother said she would drink the lemonade, but I don't know if she has, finally'

B7: Amumak eran dau limonadia.

grandmother.ERG drink AUX lemonade.ABS

'The grandmother has (indeed) drunk the lemonade'

\section{Figures}

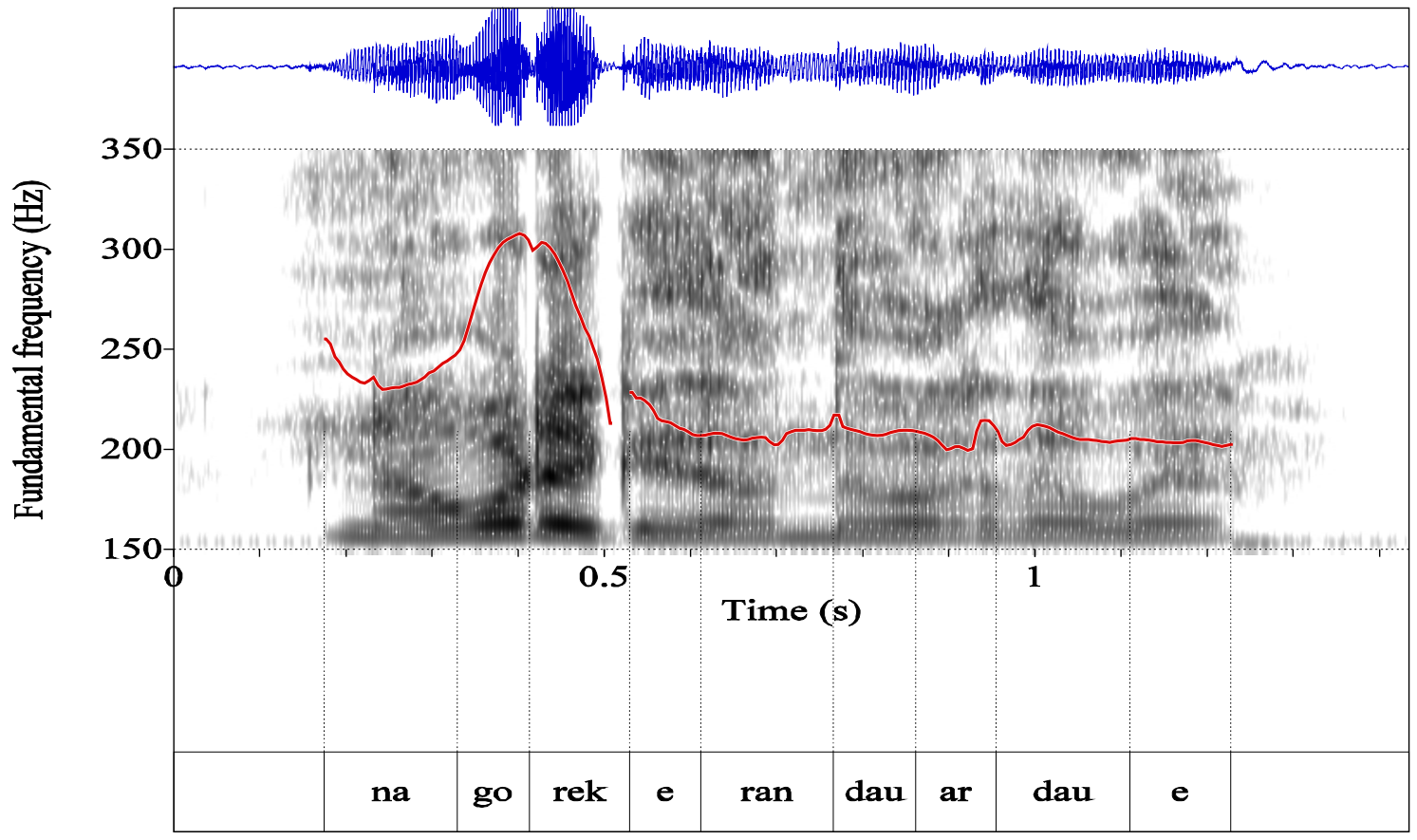

Figure 1. Representative F0 contour of an utterance with ENF on the subject (Speaker LG)

Nagorek eran dau ardaue 
'Nagore has drank wine'

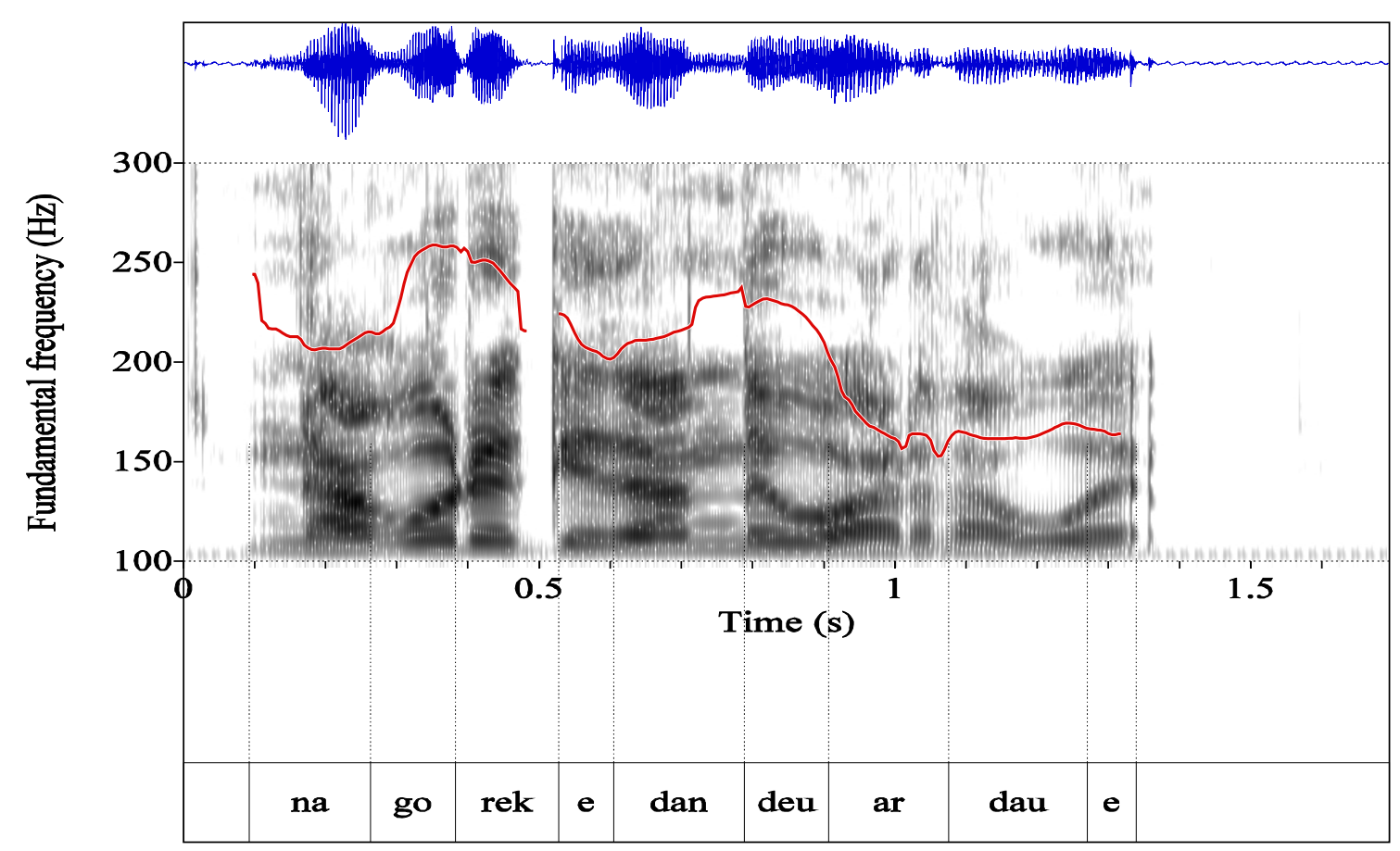

Figure 2. Representative F0 contour of an utterance with NENF on the subject (Speaker AE) Nagorek edan deu ardaue

'Nagore has drank wine'

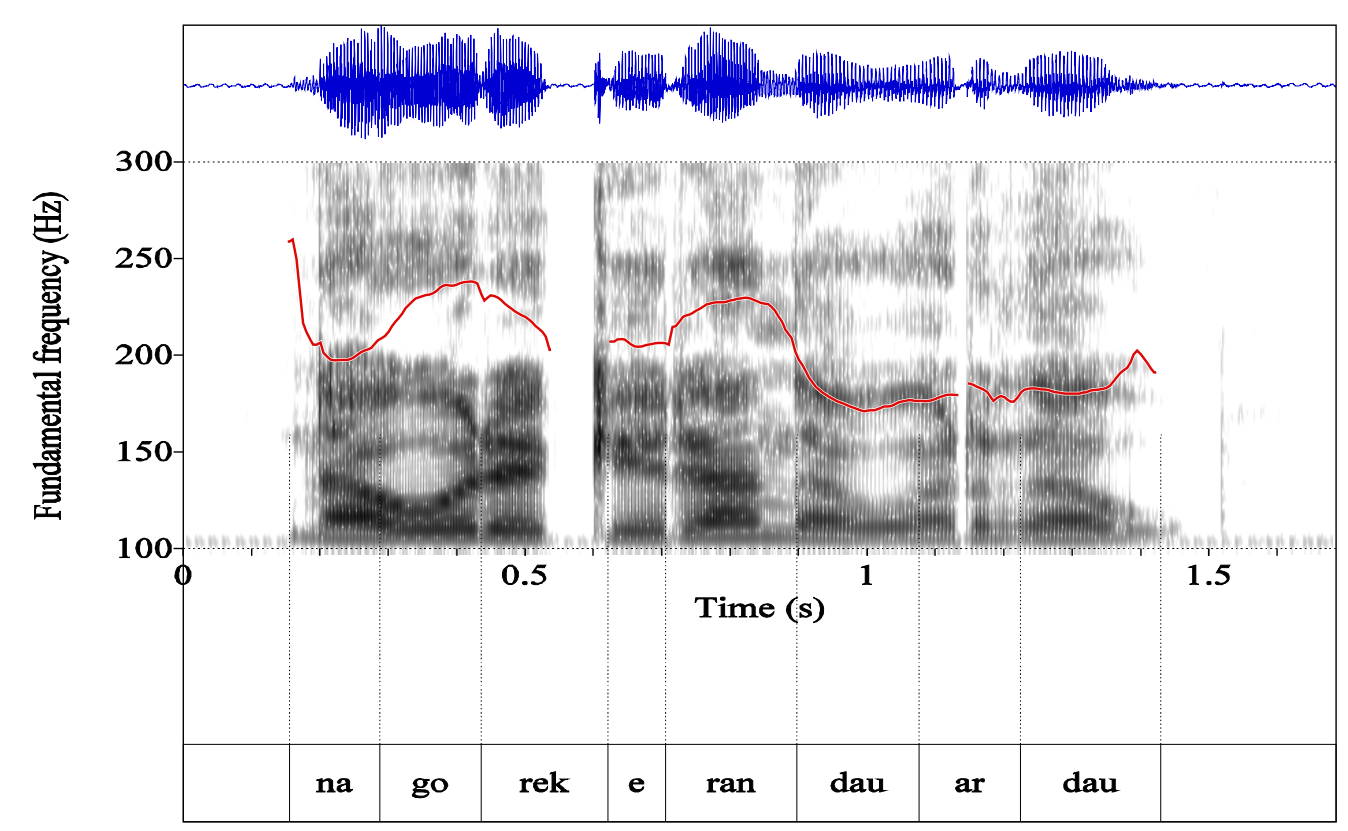

Figure 3. Representative F0 contour of an utterance with VF (Speaker AA)

Nagorek eran dau ardau

'Nagore has (indeed) drunk wine' 


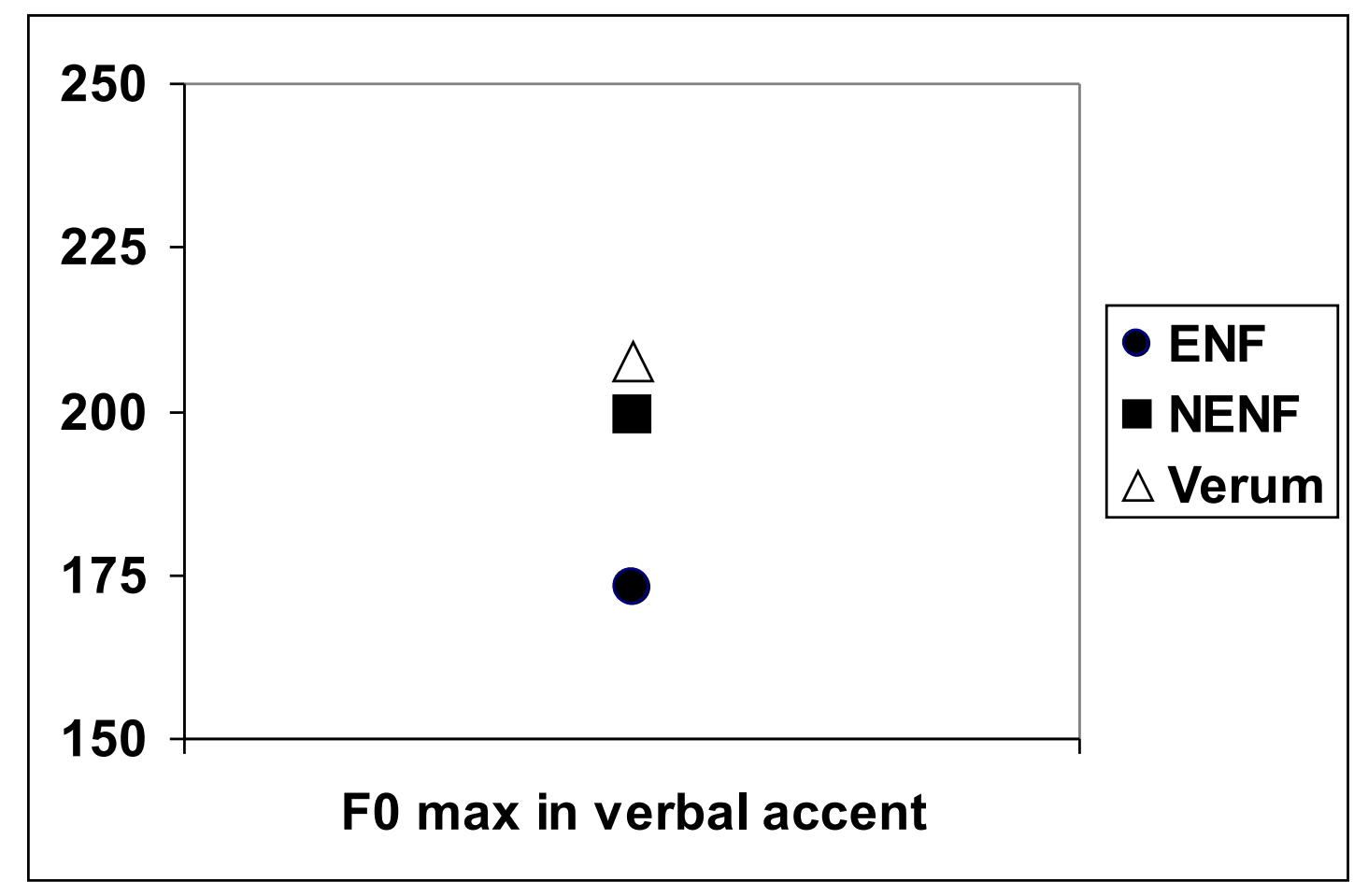

Figure 4. Scaling values of F0 maxima (in $\mathrm{Hz}$ ) in the accented syllable in the verb across the three narrow focus conditions: ENF, NENF and VF

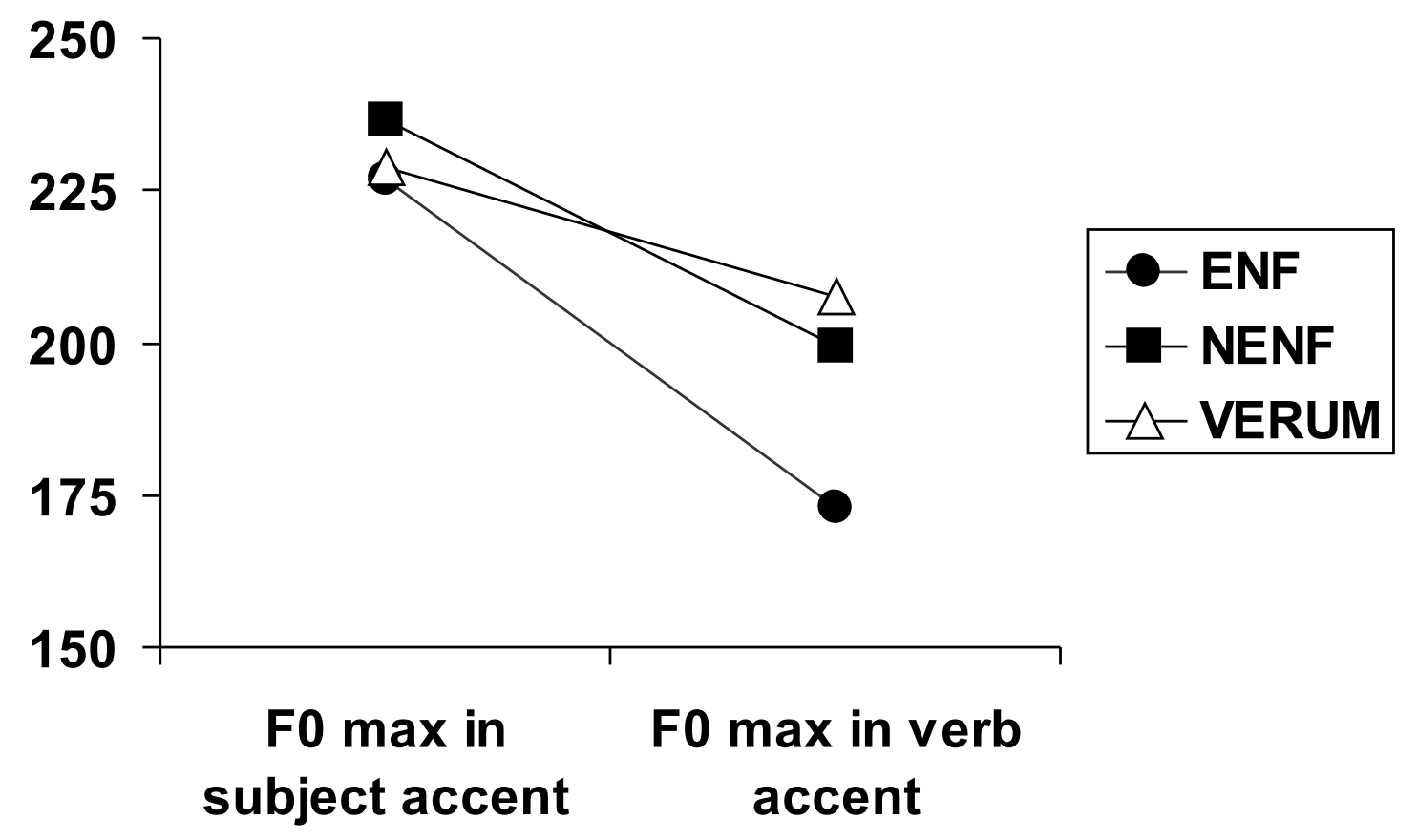

Figure 5. Scaling values of F0 maxima (in $\mathrm{Hz}$ ) in the subject and the verb across the three narrow focus conditions: ENF, NENF and VF 